\title{
Performed Substance Administration Flow Rate
}

National Cancer Institute

\section{Source}

National Cancer Institute. Performed Substance Administration Flow Rate. NCI

Thesaurus. Code C95375.

The speed of movement of the substance during the performed administration. 